USAWC STRATEGY RESEARCH PROJECT

\title{
LEVERAGING ADVANCED TECHNOLOGY IN ARMY AND AIR FORCE READINESS AND SUSTAINMENT TRAINING
}

\author{
by \\ Kathy Lindsey \\ Department of Air Force
}

Colonel Richard M. Meinhart

Project Advisor

The views expressed in this academic research paper are those of the author and do not necessarily reflect the official policy or position of the U.S. Government, the Department of Defense, or any of its agencies.

U.S. Army War College

CARLISLE BARRACKS, PENNSYLVANIA 17013 


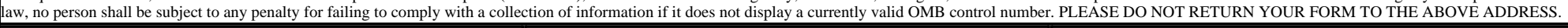

1. REPORT DATE (DD-MM-YYYY)

07-04-2003

4. TITLE AND SUBTITLE

Leveraging Advanced Technology in Army and Air Force Readiness and Sustainment

Training

Unclassified

6. AUTHOR(S)

Lindsey, Kathy ; Author

7. PERFORMING ORGANIZATION NAME AND ADDRESS

U.S. Army War College

Carlisle Barracks

Carlisle, PA17013-5050

9. SPONSORING/MONITORING AGENCY NAME AND ADDRESS

12. DISTRIBUTION/AVAILABILITY STATEMENT

APUBLIC RELEASE

13. SUPPLEMENTARY NOTES

14. ABSTRACT

See attached file.

15. SUBJECT TERMS

16. SECURITY CLASSIFICATION OF:
a. REPORT
b. ABSTRACT
c. THIS PAGE
Unclassified

17. LIMITATION
OF ABSTRACT
Same as Report
(SAR)

18

NUMBER

19. NAME OF RESPONSIBLE PERSON

3. DATES COVERED (FROM - TO)

xx-xx-2002 to $x x-x x-2003$

5a. CONTRACT NUMBER

5b. GRANT NUMBER

5c. PROGRAM ELEMENT NUMBER

5d. PROJECT NUMBER

5e. TASK NUMBER

5f. WORK UNIT NUMBER

8. PERFORMING ORGANIZATION REPORT

NUMBER

10. SPONSOR/MONITOR'S ACRONYM(S)

11. SPONSOR/MONITOR'S REPORT

$\operatorname{NUMBER}(S)$
OF PAGES RifeD@awc.carlisle.army.mil 42

\section{9b. TELEPHONE NUMBER}

International Area Code

Area Code Telephone Number

DSN 


\section{ABSTRACT}

AUTHOR: Kathy Lindsey

TITLE: $\quad$ Leveraging Advanced Technology in Army and Air Force Readiness and Sustainment Training

FORMAT: Strategy Research Project

DATE: 4 February 2003 PAGES: 42 CLASSIFICATION: Unclassified

Operational readiness and sustainment training allow military forces to be prepared for various types of contingency operations and provide for the primary means of protection and defense of United States national security interests. Readiness and sustainment training have suffered do to increased OPTEMPO and PERSTEMPO due to the rigors of missions and everyday operations, and complications brought on by budget, environmental and infrastructure constraints. This paper advocates the utilization of advanced distributed learning and distance learning in readiness and sustainment training. Advanced technology provides for a more learner-centric approach to training and can accelerate skills proficiency and retention of critical skills.

This paper also examines DoD, Army and Air Force training doctrine, traditional vs nontraditional training, human resource and work place factors, cost effectiveness and benefits, and provides recommendations for capitalizing on alternative delivery platforms. The 1 March 2002 Strategic Plan for Transforming DoD Training touts the necessity of the Services, joint community, and OSD to exploit advanced technology in Total Force training. The increased use of alternative delivery training platforms will enable Army and Air Force personnel to become more effective and efficient in their job performance. 


\section{TABLE OF CONTENTS}

ABSTRACT

LEVERAGING ADVANCED TECHNOLOGY IN ARMY AND AIR FORCE READINESS AND SUSTAINMENT TRAINING...

GUIDANCE AND DOCTRINE ............................................................................. 2

DOD TRAINING GUIDANCE............................................................................. 2

ARMY TRAINING GUIDANCE ..........................................................................

AIR FORCE TRAINING GUIDANCE ................................................................. 5

TRADITIONAL TRAINING METHODOLOGIES....................................................... 6

ALTERNATIVE DELIVERY PLATFORMS...................................................... 7

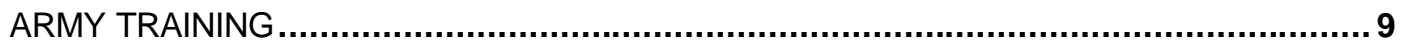

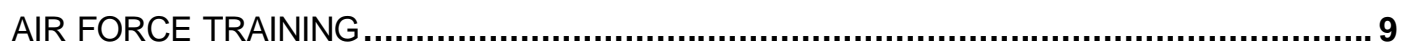

HUMAN RESOURCE AND WORK PLACE FACTORS............................................... 11

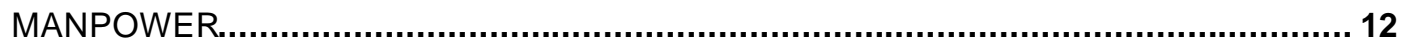

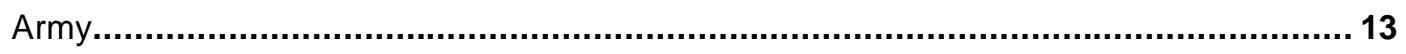

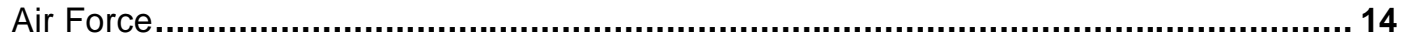

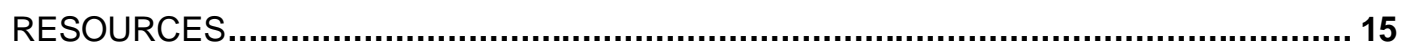

LOOKING TOWARDS THE FUTURE OF TRAINING.................................................. 16

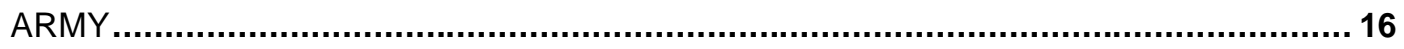

AIR FORCE ....................................................................................................... 17

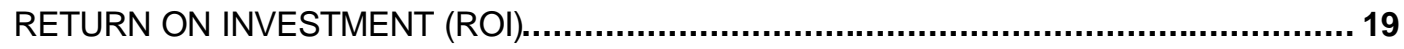

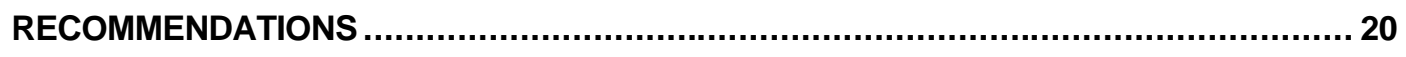

CONCLUSION

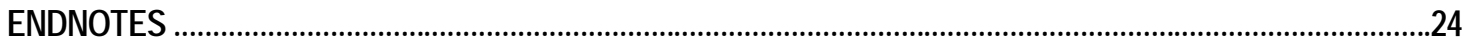


GLOSSARY

BIBLIOGRAPHY 


\section{ACKNOWLEDGEMENT}

Grateful acknowledgement is given to Colonel Nancy E. Weaver, Chief, Air Force Training Division, Directorate of Personnel Force Development, Headquarters United States Air Force, Pentagon. Colonel Weaver and her staff provided policy guidance on Department of Defense (DoD) and Air Force (AF) readiness and sustainment training; technical expertise on DoD and AF advanced distributed learning (ADL) and distance learning (DL) practices and procedures; and most importantly, continuous support in preparing this strategy research project. 


\section{LIST OF TABLES}

TABLE 1. CONVERSION OF EXSTING CONTENT TO ADL MEDIA (ACTUAL HOURS)........17

TABLE 2. CONVERSION OF EXISTING CONTENT TO ADL MEDIA (IN \$ MILLIONS)............17 TABLE 3. DELIVERY OF ADL MEDIA (ACTUAL

HOURS)...............................................18

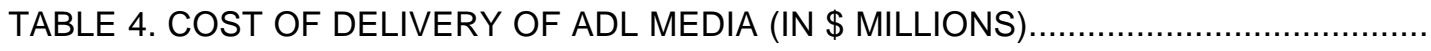
18 


\section{LEVERAGING ADVANCED TECHNOLOGY IN ARMY AND AIR FORCE READINESS AND SUSTAINMENT TRAINING}

Today's volatile world environment demands highly skilled and trained troops to match the rigors and mission requirements of combat, peacekeeping, and humanitarian assistance operations for possible deployment anytime, anywhere in the United States and throughout the world. United States government requirements for preparing, training and using highly skilled military forces for these operations are identified throughout federal policy and guidance. Past and current federal doctrine and policy, including the latest version of the United States National Security Strategy (NSS), cite the various types of possible operations that the military will be called to serve, to include domestic and foreign manmade and natural emergencies and disasters, in addition to armed conflict. ${ }^{1}$ Due to the numerous types of pending missions and the incorporation of unforeseen environmental factors that could be encountered, adequately training of military forces prior to and during deployment are paramount to the successful outcome of the operations.

As stated in the Department of Defense's Training Philosophy, "The primary objective in providing [readiness and sustainment] training is to maintain military readiness. As we draw down our force structure and budgets, it becomes all the more critical that our remaining forces be adequately trained and ready to perform their missions. ${ }^{2}$ This provides the rationale for maintaining operational readiness and sustainment of military troops via training venues across the spectrum of the Services and combined joint forces.

Downsized and strained resources in equipment, manpower, and increased personnel tempo of operations (PERSTEMPO) and mission tempo of operations (OPTEMPO) dictate the necessity to find more efficient and effective means to maintain readiness while keeping pace with emerging advanced technology. Developing, establishing, and providing training alternatives, such as advanced distributed learning ( $A D L)$ and distance learning (DL) delivery platforms to the Total Force in lieu of more traditional, formal classroom training methods, will provide a means of levering technology to streamline the readiness and sustainment training processes. Capitalizing on advanced technology can provide a much-needed boost to overcome budget and resource constraints, such as manpower, equipment, and facilities, by eliminating routine temporary duty (TDY) and per diem costs of the trainee. Advanced distributed learning can also accelerate the retention of complex warfighting and peacekeeping skills and result in increasing one's job performance. 
This paper will address the need to accelerate the exploitation of advanced technology as a viable course of action to enable the Army and Air Force to maintain and sustain agile, flexible, and prepared troops for tomorrow's operations. It will cover several aspects of fully utilizing advanced training technology by first highlighting key areas from the Department of Defense (DoD) and Service guidance and doctrine. The second section will compare traditional vs nontraditional training delivery platforms and methodology practices. The third section of this paper will investigate the limitations of today's human resource and work place factors impacting the training of soldiers and airmen. The paper will then target cost savings and tangible as well as long-term intangible benefits to the trainee and Services. Finally, it will recommend how to best take advantage of accelerating advanced technology in operational readiness and sustainment training.

\section{GUIDANCE AND DOCTRINE}

The fundamental direction of managing, developing and conducting military training (both in the traditional and non-traditional delivery and instructional platforms) begins with higher headquarters guidance to the Services and joint forces on formulating their training guidance. The incorporation of advanced technology tools and systems in the operational readiness and sustainment training environments for Army and Air Force personnel are found in the "Transformation" Department of Defense, and the Services' policy and directives. Operational readiness and sustainment training definitions of United States military members plus the previously mentioned guidance are now addressed.

\section{DOD TRAINING GUIDANCE}

Department of Defense policy directives mandate timely skills training, and include the research, development and procurement of advanced and innovative training systems for ensuring operational readiness of the United States military forces. ${ }^{3}$ The Department of Defense military training directive addresses the need for structuring training to the specific knowledge and skill requirements to enhance the proficiency of each military member, whether they are active duty, guard or reserve. The bottom-line focus of acquiring advanced and innovative systems is to integrate training modernization mechanisms into current or new training programs to enable service members to become more efficient and effective in mission accomplishment. ${ }^{4}$

Enabling and maintaining the competitive edge in current or new training programs by inserting modern training methodologies in a fast paced and somewhat restrictive environment requires the need for a Department of Defense and Services training "roadmap". These roadmaps 
will encourage a paradigm shift from more traditional means of providing training to military forces to methodologies and platforms that leverage technology to ensure a dynamic and evolving training environment. The DoD current roadmap, the Department of Defense Strategic Plan for Transforming DoD Training, requires the timely establishment and maintenance of alternative training platforms as an integral aspect of the Department of Defense and Services Transformation. ${ }^{5}$ This DoD training roadmap provides authoritative guidance to the Services to develop their respective roadmaps specifically designed to target alternative training methodologies for the Total Force. The federal directive responsible for mandating the DoD development of this strategic plan is the Defense Planning Guidance (DPG). The DPG mandates that a "Strategic Plan" for training ensures that distributed learning technologies are used to reengineer training and job performance. ${ }^{6}$

The Strategic Plan for Transforming DoD Training also cites the 2001 Quadrennial Defense Review (QDR) conclusion of embracing alternative delivery platforms in all venues of training transformation across the Services and within the Department of Defense. Advanced technology is viewed as a pivotal element in a transforming the military. As the DoD Strategic Plan states, "Leveraging the use of advanced technology is the key enabler to achieving the operational goals of the overarching Transformation of the Department of Defense."

The Army and Air Force must also follow the guidance of DoD training by preparing and providing their own subsequent training guidance and doctrine that covers a myriad of training requirements for military personnel, such as operational readiness and sustainment training. These documents provide guidance that covers the range of traditional, formal training methodologies to non-traditional training methods and delivery platforms.

\section{ARMY TRAINING GUIDANCE}

Army training doctrine, FM 25-100, encapsulates the essence of training geared towards the preparation of soldiers, leaders, and units to deploy, fight, and win in combat at any intensity level, anywhere, anytime. ${ }^{8}$ This manual also directs commanders to develop and communicate their training vision to the troops and provide the equipment and resources necessary to implement that vision. These training visions will focus on attaining appropriate levels of readiness and maintaining critical skills proficiency to match specific types of operations, such as peacekeeping, humanitarian operations or combat. 
Separate doctrine is developed to provide additional guidance on the above mentioned operations and to expand on FM 25-100. Unit and individual training criteria, commander's responsibilities, and evaluation checklists coinciding with the identified mission training are embedded in the narrative of mission requirements. Depending upon the type of mission, an extended appendix makes FM 25-100 more comprehensive in scope. Within the "deployment" sections of Army doctrine are the definitions of sustainment training and operational readiness training and the rationale for providing maintenance training on required equipment. Each of these sections is separately discussed.

FM 100-23, Peace Operations, characterizes sustainment training as a means of providing unit and individual proficiency and standards on par with mission requirements prior to or during deployment. ${ }^{9}$ Commanders are tasked to provide sufficient resources and time for soldiers to adequately train on critical skills and tasks, including common task training. FM 100-23 further states that sustainment training helps to eliminate skills 'decay' plus ensures new personnel are trained sufficiently with their counterparts. ${ }^{10}$ Sustainment training heightens the level of operational preparedness needed for possible mission requirements.

Operational readiness training provides for a "transition" of skills for individuals and units needing training in various skills and techniques before deployment to change their focus from wartime to the unique demands placed on soldiers in peace operations. Time required to train units selected for peace operations varies according to the complexity of the mission and unit. For planning purposes, units require from 4 to 6 weeks of specialized training to maintain their operational readiness. ${ }^{11}$

The primary purpose of maintenance training is to keep equipment ready for combat or training exercises. ${ }^{12}$ Once individuals have attained appropriate degrees of skills proficiency, they must be provided with opportunities to practice these skills and tasks to sustain that level of performance. ${ }^{13}$ Sustainment and operational readiness training cannot be conducted in a vacuum. Equipment and weapons systems must be included as an integral part of the mission requirement.

Key to the successful accomplishment of sustainment, operational readiness, and maintenance training of service members, generally depends on the following: the unit and the OPTEMPO of personnel; the turnover and turbulence within the unit; their [initial] levels of proficiency; and the resources readily available to the unit. ${ }^{14}$ Army training doctrine also cites the necessity of providing non-traditional instructional methods and delivery platforms to 
strengthen or replace existing training when opportunities for matching emerging technologies or manpower and/or budget constraints present themselves.

\section{AIR FORCE TRAINING GUIDANCE}

As with the Army, operational readiness and sustainment training criteria for Air Force personnel are found in similar doctrine. The Air Force developed doctrine addressing the necessity of maintaining readiness for tomorrow's mission and the preparedness of the military troops to support the commander's needs. ${ }^{15}$ Air Force Policy Directive 10-2 defines readiness as "the ability of AF forces to deliver their designed outputs without unacceptable delay." ${ }^{16}$

Key elements of operational readiness are the preparation of personnel (active duty, reserve, and guard units) and equipment to achieve, maintain, and sustain required readiness levels to meet military peacetime and wartime taskings. Matching the proper skills mix to the mission objectives accelerates the identification of proper and timely training. The Air Force codes, trains, and assigns personnel to meet individual and unit requirements and schedules training exercises to enhance readiness and improve crisis response. ${ }^{17}$ Each phase of the airmen's career is designed to provide the continuity of skills progression [embedded] training that will enable the Air Force to best utilize their resources. This type of progression is called the "training continuum" cycle that includes elements of skills proficiency maintenance training.

Specialty skills training policy and guidance for Air Force personnel, both civilian and military, can be found in the Air Force Instruction (AFI) 36 series (Personnel) regulations. The training AFls cover the overall management, development, and conducting of formal classroom and non-traditional training to obtain and maintain the specialty skills of airmen. ${ }^{18}$

Proficiency skills training targets the Air Force Specialty Code (AFSC) of all active duty, guard and reserve personnel. Mandated specific AFSC requirements are addressed in Career Field and Education Training Plans (CFETPs). These plans encompass the following: the critical skills levels and matches the proficiencies of the training; at what point in the individual's career progression the training needs to convene; and addresses the mechanism of how the delivery of training is to take place. Both traditional and non-traditional delivery platforms can be used in lieu of formal classroom instruction at the technical training wings and field training detachments. ${ }^{19}$ 
As the definitions of operational readiness and sustainment training were covered in the previous sections, the mechanism of the differences between the deliveries of training to the trainee needs to be addressed. A comparison of traditional (formal classroom) training to more non-traditional "classroom without walls" and training modernization concepts of learner-centric training will be discussed in the next section.

\section{TRADITIONAL TRAINING METHODOLOGIES}

Traditional formal training for both Army and Air Force personnel is normally defined by the following scenario: 12 to 20 students seated in the schoolhouse led by an instructor lecturing from the technical curriculum for an extended length of time. The duration of the training is usually conducted under the guise of "group or lock step" advancement. ${ }^{20}$ End of block or end of course tests, or other measurement and evaluation instruments are given to the trainees to measure their knowledge and retention of skills. However, if the training equipment is not readily available at the schoolhouse (otherwise known as a training deficiency), memos are submitted to the trainees' supervisors indicating that training must take place at home station or an alternate location where this equipment is available.

To demonstrate readiness proficiencies, opportunities for exercises, simulations, and scenarios are provided to soldiers and airmen on a semi-annual or annual basis in the field/home station at the unit level. Operational readiness and sustainment training can take place either locally or at the formal training centers in another location requiring travel and billeting costs. These readiness training opportunities can be hampered due to the sheer costs and magnitude of conducting training (TDY and per diem costs), lack of facilities (schoolhouse, dorms, and dining facilities), and finally scheduling the training during heightened OPTEMPO and PERSTEMPO periods.

Specialty skills training for the Army is normally conducted at formal training classrooms at the Combat Training Centers (CTCs) and encompasses peacekeeping, humanitarian operations, and combat support tactics training. Normally, elements of training at the unit or home station are based on the decision of the unit commanders. One major decision that impacts training is keeping up with technology and personnel OPTEMPO. This is a major challenge for unit commanders and must be included in the training requirements. ${ }^{21}$ Several cases of readiness training applications not being on par with advanced equipment have been 
documented and will continue to degrade readiness capabilities. These limitations will continue to impact readiness if not corrected. ${ }^{22}$

The Air Force projects a limited number of training requirements one to two years in advance at the unit level. These requirements are funneled to the major commands and then submitted to the Air Staff for TDY and per diem funding. After the requirements are "matched" by the identified specific specialty skills of personnel needing the training, course schedules are built by the technical training wings and field training detachments for a short duration. However, due to the limited funding, not all personnel requiring training can attend during that fiscal year and must wait until funding is available, or have their home unit fund their TDY and per diem costs.

In addition to the operational readiness and sustainment training described above, the Army and Air Force must also incorporate separate advanced distributed learning and distance learning roadmaps required by the Strategic Plan for Transforming DoD Training. These roadmaps: outline the budget requirements geared towards the fiscal year defense program (FYDP) accomplishment; address ADL and DL definitions; and state the rationale, benefits, and challenges of exploiting advanced technology in training. It is these alternative training delivery platforms that will be covered in the next section.

\section{ALTERNATIVE DELIVERY PLATFORMS}

The exploitation of advanced technology tools can be considered an integral aspect of the revolution in military affairs (RMA) as it provides new systems that enhance the capabilities of the warfighter to accomplish the mission objectives in a more expedient manner than traditional training. According to a recent Defense Science Board Task Force Review on Training Superiority and Training Surprise, applying advanced technology in all training venues can be identified as a "revolution" in training. ${ }^{23}$ Therefore, the Services and joint community should take full advantage of capitalizing on opportunities to insert it in their formal training environments.

This Defense Science Board Task Force further stated that:

"A second training revolution is brewing which makes it necessary that future training must be delivered to the individual, to units, and to joint forces, when it is needed [in the field and unit], not in the schoolhouse after which there is time for skills proficiency to decay. The application of computer technology in particular will aid in the control of individual decay of readiness skills by delivering training at the point of need and will enable complex training to be developed and applied inexpensively. ${ }^{24}$ 
The use of computers and other advanced technology applications in the current training environments attest to the agility and flexibility of using ADL and DL in readiness and sustainment training. Advanced technology is viewed as a "force multiplier" that provides training anytime, anywhere.

Alternative and advanced technology training platforms are defined in various $\mathrm{DoD}$ and Services doctrine pertaining to implementing advanced technology in all facets of training to enable military forces to maintain critical readiness skills and proficiency. According to the overarching DoD Advanced Distributed Learning Implementation Plan, distributed learning (DL) is defined as structured learning that takes place without requiring the physical presence of an instructor. Distributed learning is a synchronous and/or asynchronous learning melded with technology and may use one or more of the following media: audio/videotapes, CD-ROMs, audio/video teletraining (VTT), correspondence courses, computer based instruction (CBI), computer based training (CBT), interactive television (IVT), interactive courseware (ICW), and video conferencing.

The DoD Implementation Plan for Advanced Distributed Learning describes ADL as a means to provide more effectives means of training individuals regardless of location. The overarching objective of the DoD ADL initiative is to provide a federal framework for providing quality education and training via alternative delivery platforms to service members in a costeffective and quality manner that matches the trainees' needs anytime, anywhere. ${ }^{25}$ "Advanced distributed learning (ADL) is an evolution of distributed learning (distance learning) that emphasizes collaboration on standards-based versions of reusable objects, networks, and learning management systems, yet may include some legacy methods and media. ${ }^{26}$ The most highly visible and rapidly advancing form of providing training via ADL is through web-based training (WBT) platforms.

As this advanced technology expands to the readiness and skills training requirements and is provided directly to the user/trainee at the work center and in the field, guidance must be provided by the Secretary of Defense (SECDEF) to the Services on expectations of applications of technology in training, such as conversion and delivery milestones, funding, manpower issues, and technology insertion in schoolhouses and training centers. One primary goal addressed in the DoD ADL Implementation Plan is the task of building and providing advanced technology to Service personnel that will also aid in the combatant commanders' requirements for mission accomplishment. The DoD ADL Implementation Plan's primary goal is to develop a robust 
environment that provides for superior military capabilities across the Services that encompass the requirements of the combatant commanders. ${ }^{27}$

All Services were tasked by the SECDEF to provide subsequent advanced distributed learning roadmaps addressing the following subjects: projected milestones, challenges to implementation, and responsibilities of embedding technology into their training and education requirements to maintain readiness of their forces, and determine solutions to budget and OPTEMPO and PERSTEMPO constraints.

While the doctrine, guidance and methods of advanced distributed learning and distance learning have been addressed, an examination of Army and Air Force training expectations is needed to fully appreciate the challenges of applying these new training concepts. The next section will address Army training doctrine as it applies to alternative delivery platforms. ARMY TRAINING

Using advanced technology in Army readiness training is viewed as a mission enhancer that provides an outlet for responding to the Army transformation goals of the objective force. The DoD ADL Implementation Plan tasks the Army to include alternative delivery platforms in training and education programs as a catalyst for mission accomplishment. The DoD ADL Implementation Plan identifies the Army as providing timely training to their soldiers via alternative delivery platforms. "The Army will improve training, enhance force readiness, and support Army transformation by exploiting current and emerging distance learning technologies to develop and deliver quality training and education materials to all Army personnel anytime, anywhere. ${ }^{.28}$

One form of advanced technology proven to enhance Army readiness is the use of simulation and virtual training concepts. These concepts help solve the problems associated with the dangers of using live ammunition and hazardous conditions, decreased availability of ranges, and the rigors of traditional training. These scenarios dictate the necessity of providing alternative readiness and sustainment training options. The Army Modernization Plan 2002 describes this predicament for leaders and how to rectify the situation using alternative delivery platforms where it stated: "Virtual training systems assist commanders with the building and sustaining of training readiness. Virtual training also has the advantage of allowing Soldiers to perform tasks to dangerous for the live environment, provides the capability for rapid changes to scenarios, and facilitates retraining specific tasks until training objectives are met. ${ }^{.29}$ AIR FORCE TRAINING 
The Air Force is also actively capitalizing on inserting advanced technology in the formal classroom environment, as well as providing a "user friendly" means for transferring knowledge to the Airmen at their work center or at deployment locations. The DoD ADL Implementation Plan cites the Air Force's on-going comprehensive review of advanced distributed learning and distance learning conversion opportunities from the more traditional training environments. The Air Force has determined a standards-based ADL program is best suited for training. These standards have been adopted from industry, academia and government best practices to serve as a basis for successful implementation. ${ }^{30}$ The Air Force Strategic Plan ties the Department of Defense advanced technology goals and objectives with Air Force transformation goals that will encompass all facets of training and education. An assessment of providing training via alternative delivery platforms must begin by conducting reviews of current training practices that includes instructional design and delivery of the courses, and the evaluation of the retention and performance of skills proficiency.

As addressed in the Air Force Advanced Distributed Learning Strategic Plan, the conversion of courses (modifying the curriculum from traditional platform instruction to alternative delivery platforms) can encompass various applications of distance learning, such as technology insertion, interactive courseware (ICW), paper-based products, video teletraining (VTT), or webbased training. Some advantages of applying new technology into current courses are the prospects of accelerated learning, portable training, and application of adult learning theories aiding in the retention of training.

Increased use of technology can be found in formal classroom environments in the technical training wings, field detachments, and unit level operations. One example of lowering training costs while increasing student interaction and retention skills is in $\mathrm{KC}-10$ apprentice crew chief training at McGuire Air Force Base, New Jersey. According to a recent article reporting on the benefits of the aircraft maintenance training, students can trace electronic circuits, track fuel flow and locate potential maintenance problems throughout the aircraft-before

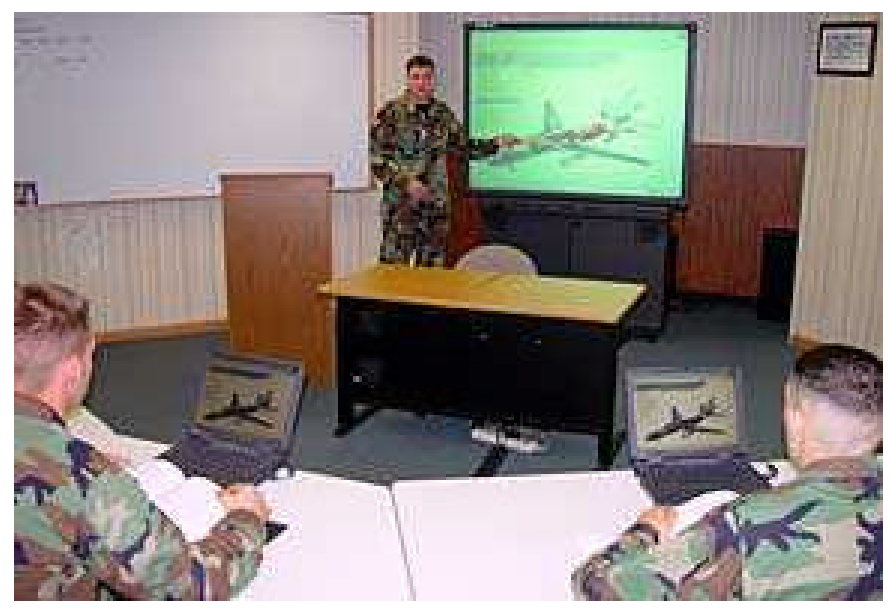


placing a hand on the jet. This training technology for crew chiefs encompasses various aircraft systems by virtual means. The projected cost of setting up the classroom with this advanced technology per three students is less than $\$ 7,000 .^{31}$

\section{FIGURE 1. CLASSROOM 2005 TECHNOLOGY}

This type of training provides access to different pieces of equipment by virtual means that may not otherwise be available or are in constant demand in the field. The overall cost comparison of acquiring and maintaining the advanced technology training equipment outweighs the training "down time" or shortfalls that may be encountered stemming from the acquisition piece of purchasing engine parts. These types of shortfalls are prevalent for all services and provide a significant basis for using alternative technologies. One training and simulation article recently stated, "Military forces around the world are continuing to face budget constraints, human resource shortages, and shifting priorities. These issues sometimes result in less-thanideal training capabilities. ${ }^{32}$

Utilizing technology in operational readiness and sustainment training can assist in alleviating the OPTEMPO and PERSTEMPO and budget problems facing the military in a volatile world environment, while simultaneously facing a transformation of its forces. The following section describes these limitations that directly impact the Army and Air Force readiness factors.

\section{HUMAN RESOURCE AND WORK PLACE FACTORS}

Challenges face the military everyday due to daily operations and the downsized number of personnel responsible for accomplishing the mission at the work center or in the field. These challenges, indicative of streamlining the work processes and flattening the organization, are otherwise known as "doing more with less". Compounding these issues is the possibility of overseas deployment for an [unknown] extended period of time. Timely and innovative training that accommodates combatant commanders' requirements must be on the forefront by providing flexible and agile readiness training to the troops to maintain skills proficiency before, during, and after deployments.

Military readiness today is adversely impacted by the OPTEMPO and PERSTEMPO, the broad variety of missions, and the many complex weapons systems in use or being introduced into the armed forces. The Secretary's stated vision [in the DoD ADL Implementation Plan] of 
"anytime, anywhere" learning using advanced learning technologies represents a visionary approach to many of the Department of Defense's learning challenges. ${ }^{33}$

Based on my research and instructional training experience, advanced distributed learning and distance learning training delivery platforms offer the catalyst of providing direct training to the troops in a shorter amount of time compared to the traditional, formal classroom approaches. ${ }^{34}$ These training alternatives also diminish the severity of compounding an already over tasked mission schedule for soldiers and airmen at their home station. Commanders have been hesitate to approve the trainee leaving the unit and going TDY to attend a formal training course away from the military members' home station, while other personnel perform the absent trainee's duties as well as their own.

As the rate of technology increases and more advanced equipment becomes available on the horizon, training becomes the pivotal mechanism that will provide skills enhancement in the future. The key phrase, "agile and flexible", becomes paramount at the work center and in the field. Operational readiness demands "ready" and "able" troops (both individually and collectively as a unit) that can effectively respond to mission taskings predicated by adequate training. Advanced distributed learning can aid to the appeal of readiness training for service members at the unit, field exercises or simulations, formal classrooms, or combat training centers. Advantages of one type of DL capabilities are found in the Department of Defense's Strategic Plan for Transforming DoD Training when it identified that: "Distance learning can shorten formal training time, decrease time away from home, increase available days to the unit, enable improved mobilization processes, and provide refresher/new equipment training to more inexperienced personnel. ${ }^{.35}$ Readiness training cannot be static (not evolving with the advanced approaches or equipment), or the military force's adjustment to new technology will become a tedious and cumbersome venture. The Services must respond quickly to the rapid changes to technology and be able to adapt to these changes. These technological advances can be viewed as both opportunities and challenges to keep up with the pace. ${ }^{36}$

While the Army can facilitate a smoother transition from their current OPTEMPO that impacts operational readiness training by capitalizing on advanced technology there are other issues that impact readiness and sustainment training. This next section will highlight key areas affected by manpower and resources that effect readiness.

MANPOWER 
The impact and tempo of mission taskings on soldiers and airmen are emphasized by the services training doctrine and are used as rationales for incorporating alternative delivery platforms. Two DoD mandates are imposed on the services for leveraging ADL in training: the first encompasses the use of internet (web-based training) and the second is the need to respond to the challenges of manpower reductions and high OPTEMPO. Both challenges directly impact current education and training systems at the technical training wings and field training detachments. ${ }^{37}$

ARMY

The Army is targeting its focus on the OPTEMPO and PERSTEMPO of the soldier and exploring the advantages of using $A D L$ and $D L$ in readiness and sustainment training. Several factors impede readiness and sustainment training at unit level or home station in accordance with Army training doctrine: non-mission taskings, an excessive operational pace, and a shortage of training resources. ${ }^{38}$ Guidance must accurately establish the proper parameters and outlets for measuring effectiveness of utilizing advanced technology in lieu of relying on formal classroom training, which may be otherwise impeded by adverse or less than ideal conditions.

However, both positive and negative aspects of using advanced technology in readiness training should be addressed. Advanced technology must be viewed by leaders as an integral tool of training to exploit at full advantage, thereby allowing soldiers the opportunity to train on the new equipment prior to critical skills or proficiency training. Technology should be an enabler, not a hindrance or burden to task completion. The Army Modernization Plan 2002 advises leaders to stay abreast of advanced technology to enable them to seamlessly incorporate the new equipment in readiness training. This will allow the soldiers to remain effective and proficient in their skills that are geared towards Objective Force development. ${ }^{39}$

Numerous studies have concluded that training via advanced technology vehicles aids in critical specialties - those that cannot afford (both figuratively and literally speaking) to attend a formal training course. Additional problems can ensue from the lack of trained personnel. Not only does this impact overall operational readiness of the unit and to the military as a whole, but in certain critical skills, augmentees may be used on site to take up the slack. They, in turn, may lack the adequate proficiencies to accomplish the day-to-day mission objectives and require on the job training (OJT), which exacerbates the problem. Allowing the trainee to accomplish the proficiency training via advanced distributed learning at the work site saves time, manpower, and funding. The Army Modernization Plan 2002 stresses opportunities for training via distance 
learning platforms for non-commissioned officers (NCOs). If training is not accomplished in a timely fashion, the resulting impact may be an increase in the shortage of personnel with critical skills. Utilizing distance learning can reduce the potential for future personnel shortages and provide extended cost savings at the work center. ${ }^{40}$

Furthermore, the use of advanced technology in today's Army in critical skills training that prepares and maintains the Army's readiness will provide a long-reaching effect into the transformation policies of the future. One method of accomplishing this is to decrease the time away from the work center by providing training to the actual location of the trainee which also keeps the unit intact, thereby decreasing the potential of work overload to the remaining soldiers. Mission tasking impact training schedules for soldiers before, during and after deployment and operational assignments. Using $\mathrm{DL}$ and $\mathrm{ADL}$ will minimize absences from the work center due to TDY schedules. This will also result in keeping the unit together for easier and more effective training transactions. ${ }^{41}$

Given that personnel shortages pose readiness problems for the Army, Distance Learning might have an impact on alleviating a shortage in certain military occupational specialties (MOS). This is based on Distance Learning's potential for being faster and more efficient than traditional residential training. Distance Learning can contribute to lessening the impact of critical MOS shortages by providing timely readiness and proficiency skills training. It will also aid in the effectiveness of potential cuts in personnel shortages in critical fields. ${ }^{42}$

AIR FORCE

The Air Force is also realizing the potential of using advanced technology for the Total Force to help decrease OPTEMPO and PERSTEMPO effects. Advanced technology is viewed as a force multiplier and an enabler for training aimed at the right personnel, at the right place and at the right time. The Air Force Chief of Staff recently stated his concern about the current pace of mission tasks. One method of decreasing this problem is to plan for the future by establishing funding for the FYDP and matching ADL and DL requirements for readiness and sustainment training in critical skills. ${ }^{43}$

Guard and reserve forces are also included in this funding and resource equation of utilizing advanced technology to aid in the critical skills and manpower shortages. Overarching guidance from the Department of Defense down to the headquarters Air Force level addresses the impact of technology on readiness. Inconsistencies in the maintenance of proficiency of specific skills can also be attributed to the lack of training facilities, equipment conditions, and training 
schedules of guard and reserve personnel. The application of providing innovative training solutions to operational readiness encompasses both active duty and reserve forces. A recent study conducted in training simulations cite the need for extending advanced technology platforms to guard and reserve personnel due to the uniqueness of their job profiles, the lack of training time and facilities, and the location of their units. ${ }^{44}$ The lack of adequate facilities and availability of equipment are examples of the negative impact resources have on operational readiness training for soldiers and airmen.

\section{RESOURCES}

Total Force Army and Air Force personnel have encountered training shortfalls and deficiencies due to several environmental factors. One major problem cited is encroachment problems [legal and/or environmental restrictions of land and property no longer available for military training purposes due to noise levels, endangered species within the area, and historical or sacred sites, etc.]. The lack of proper equipment available at the work center or training site and minimal contractor training support on new, fielded technology prior to operational and maintenance training also poses problems. As more and more constraints are placed on the Services for training, other avenues must be explored to guarantee operational readiness. These examples are indicative of the growing concern of senior leaders in establishing short term and long term solutions to readiness and sustainment training. The 2002 Training and Simulation Trends and Technology Review magazine quoted BG Stephen M. Seay as stating: "Emerging threats to U.S. national security and growing restrictions on the services' ability to conduct live training are key reasons why advanced simulators and virtual combat environments must be adaptable and, preferably, portable. ${ }^{, 45}$

The Army and Air Force are providing their personnel with timely training and oversight of advanced technology processes and delivery of training and equipment due to the benefits of incorporating new technology into training. One cited rationale as to why distance learning is advancing in acceptance in the Services follows:

"Distance Learning moves a significant portion of training from the traditional schoolhouse into locations near where the soldiers reside, making it easier for them to attend. By not acquiring soldiers to leave their units for courses elsewhere and by providing significant amounts of training in self-paced modes, Distance Learning provides the potential of increasing flexibility and continuity in the timing of training. ${ }^{, 46}$ 
The previous section addressed the rationale of providing alternative delivery platforms to the Air Force and Army due to work place, resource and manpower factors. Measures of Services effectiveness are attributed to an increase in the number of personnel trained in a shorter amount of time and a decrease in dollars spent for travel and per diem costs associated with sending personnel to the technical training wings and field detachments for readiness and sustainment training. The following section will examine the return on investment costs and projected benefits of providing ADL and $\mathrm{DL}$ tools in operational readiness and other forms of training for Army and Air Force personnel.

\section{LOOKING TOWARDS THE FUTURE OF TRAINING}

The Department of Defense has issued an overarching goal to the Services on course conversion and savings. The DoD Advanced Distributed Learning Implementation Plan emphasizes this primary goal of obtaining a 30 per cent reduction in training costs throughout the Services and DoD through the use of advanced technology in education and training. ${ }^{47}$ This reduction is accomplished by the conversion of current or projected courses by advanced technology through a variety of delivery platforms, such as technology insertion, a mixture of paper-based materials and new technology, advanced distributed learning, and distance learning mechanisms.

Investments in alternative delivery platforms in operational readiness training and other types of training will target towards the FYDP, plus be measured in increments over the same period by comparison of acquisition, delivery and implementation milestones for success. Training requirements will be matched with available and projected resources across the FYDP, thus enabling leaders to project and submit their service members' training requirements for the Program Objective Memorandum (POM). The bottom line for the Army is to provide alternative delivery platforms in training to match their mandated training transformation efforts. The following section addresses the projected $A D L$ and $D L$ costs and investments of the Army across the FYDP for providing readiness and sustainment training to their soldiers. ARMY

The DoD ADL Implementation Plan has tasked the Army to improve their training by leveraging advanced technology thereby enhancing readiness and sustainment and supporting the Army's transformation efforts. The training will be provided to soldiers worldwide, regardless of location. ${ }^{48}$ The initial investment in distance learning required over the FYDP is not limited to costs of equipment or paying for contractor fees and services. The overall program consists of 
the initial investment, maintenance, and upgrades to the equipment. These costs also include (dependent upon the type of distance learning being practiced) the training of students, hiring of instructor personnel, and instructional development. The initial investment in distance learning for the Army is approximately $\$ 630 \mathrm{M}$ over the FYDP. This covers infrastructure costs, courseware design and development, and the costs of delivery and implementation of training at the work center. ${ }^{49}$

\section{AIR FORCE}

The Air Force has defined the distance learning and advanced distributed learning initiative under the guise of a training concept of operations (CONOPS). Training CONOPS will provide a channel for modernization efforts and leverage the ability to "reach" all Airmen regardless of location to continue with their skills progression and not have an unnecessary break in training. Training CONOPS also ties resources with requirements - a means to project and provide for funding during the FYDP cycles.

According to the Air Education and Training Command (AETC), the average cost for the Air Force to invest in course conversion (modifying a current instructor led course to a student centric course) is $\$ 10 \mathrm{~K}$ per hour of presentation, or amounts to $\$ 250 \mathrm{~K}$ to $\$ 480 \mathrm{~K}$ per 80 hour (two week) course. So far, the average conversion cost has been $\$ 350 \mathrm{~K}$ per course. This conversion rate deducts the TDY and per diem costs since the trainee does not travel to the schoolhouse or need lodging and meals. AETC anticipates the overall projected cost savings for a two week course range from $\$ 16 \mathrm{M}$ for $\mathrm{FY} 03$ to $\$ 18 \mathrm{M}$ in $\mathrm{FY} 07 .{ }^{50}$ These costs savings show a significant return on initial investment over the FYDP.

These savings are attributed to the proper identification of courses that are conducive to partial (technology insertion) or whole (total ADL or DL formats) conversion. The courses which are more appropriate for conversion are generally those that are labeled "knowledge objectives" training formats, as opposed to more performance objectives which may not translate well by alternative delivery formats. The savings generated are attributed to initial investments of ADL and DL formats compared to the TDY and per diem costs over the FYDP. These return on investment $(\mathrm{ROI})$ savings encompass the conversion of identified courses and the cost of delivery to the trainees. The next section will cite the projected costs for the Army and Air Force across the FYDP addressed in the Department of Defense ADL Implementation Plan from the component investment (in hours and millions of dollars) from the training requirements data call. ${ }^{51}$ 


\begin{tabular}{|l|c|c|c|c|c|c|c||}
\hline & FY00 & FY01 & FY02 & FY03 & FY04 & FY05 & TOTAL \\
\hline AF & 203 & 142 & 386 & 384 & 354 & 72 & 1,541 \\
\hline ARMY & 3,045 & 2,042 & 3,978 & 4,926 & 5,030 & 5,892 & 24,913 \\
\hline TOTAL & $\mathbf{3 , 2 4 8}$ & $\mathbf{2 , 1 8 4}$ & $\mathbf{4 , 3 6 4}$ & $\mathbf{5 , 3 1 0}$ & $\mathbf{5 , 3 8 4}$ & $\mathbf{5 , 9 6 4}$ & $\mathbf{2 6 , 4 5 4}$ \\
\hline
\end{tabular}

TABLE 1. CONVERSION OF EXSTING CONTENT TO ADL MEDIA (ACTUAL HOURS)

Table 1 indicates the total hours of identified [knowledge objective] courses that will be converted to alternative delivery platforms. The ADL media hours signify curriculum that is currently presented by an instructor in a formal classroom to web-based training platforms or other methods of $A D L$.

\begin{tabular}{||l|c|c|c|c|c|c|c||}
\hline \hline & FY00 & FY01 & FY02 & FY03 & FY04 & FY05 & TOTAL \\
\hline AF & 1.650 & 0.766 & 6.500 & 5.190 & 3.110 & 0.660 & 17.876 \\
\hline ARMY & 20.902 & 22.651 & 24.778 & 28.411 & 31.074 & 28.062 & 155.878 \\
\hline TOTAL & $\mathbf{2 2 . 5 5 2}$ & $\mathbf{2 3 . 4 1 7}$ & $\mathbf{3 1 . 2 7 8}$ & $\mathbf{3 3 . 6 0 1}$ & $\mathbf{3 4 . 1 8 4}$ & $\mathbf{2 8 . 7 2 2}$ & $\mathbf{1 7 3 . 7 5 4}$ \\
\hline
\end{tabular}

TABLE 2. CONVERSION OF EXISTING CONTENT TO ADL MEDIA (IN \$ MILLIONS)

Table 2 indicates the initial investment of converting the hours in Table 1 to ADL over the FYDP. These conversion costs include the contractor support (or the in-house support) of designing and developing the selected methodology of delivery, but does not include the delivery costs. For example, the computer programming and graphics design costs will be included. 


\begin{tabular}{||l|c|c|c|c|c|c|c||}
\hline & FY00 & FY01 & FY02 & FY03 & FY04 & FY05 & TOTAL \\
\hline AF & 118 & 321 & 463 & 849 & 1,233 & 1,587 & 4,571 \\
\hline ARMY & 195 & 3,045 & 2,042 & 3,978 & 4,926 & 5,030 & 19,216 \\
\hline TOTAL & $\mathbf{2 1 3}$ & $\mathbf{3 , 3 6 6}$ & $\mathbf{2 , 5 0 5}$ & $\mathbf{4 , 8 2 7}$ & $\mathbf{6 , 1 5 9}$ & $\mathbf{6 , 6 1 7}$ & $\mathbf{2 3 , 7 8 7}$ \\
\hline
\end{tabular}

TABLE 3. DELIVERY OF ADL MEDIA (ACTUAL HOURS)

Table 3 reflects the total hours of the delivery cost of the course after it is converted. This translates to the number of hours necessary for the student to complete the course over a period of time. For example, the training may be delivered by interactive video television (IVT) in two to three hour increments. Delivery (or broadcast time) is included in the overall costs over the satellite networks.

\begin{tabular}{||l|c|c|c|c|c|c|c||}
\hline \hline & FY00 & FY01 & FY02 & FY03 & FY04 & FY05 & TOTAL \\
\hline AF & 2.842 & 1.573 & 4.786 & 2.391 & 2.533 & 2.587 & 16.712 \\
\hline ARMY & 75.878 & 70.955 & 76.430 & 64.270 & 70.838 & 82.824 & 432.195 \\
\hline TOTAL & $\mathbf{7 8 . 7 2}$ & $\mathbf{7 2 . 5 2 8}$ & $\mathbf{8 1 . 2 1 6}$ & $\mathbf{6 6 . 6 6 1}$ & $\mathbf{7 3 . 3 7 1}$ & $\mathbf{8 5 . 4 1 1}$ & $\mathbf{4 4 8 . 9 0 7}$ \\
\hline
\end{tabular}

TABLE 4. COST OF DELIVERY OF ADL MEDIA (IN \$ MILLIONS)

Table 4 indicates the cost of delivery to the trainee of the converted courses. For example, web based training costs are associated with the bandwidth necessary to accommodate this type of training.

\section{RETURN ON INVESTMENT (ROI)}

One example of cost savings for the Air Force (in the training arena) is the use of advanced distributed learning techniques and applications to readiness type training. The cost savings are significant in the conversion of technical training orders via computer technology as compared to the use of more traditional paper based products. Placing technical and maintenance orders on compact disks in lieu of paper based ones will save the Air Force more than $\$ 25,000$ per year for each technical and maintenance order. ${ }^{52}$ Having this practice instituted as an operational standard throughout the Air Force will generate significant cost benefits in the long run, especially since this is a day-to-day operational task.

The Army could reap significant benefits in savings from the utilization of advanced technology for readiness training instead of attending formal, traditional courses. The most costly expenditures stem from the TDY and per diem costs as alluded to in previous sections. In the recent Air Force Report of Other Services' Advanced Distributed Learning Practices, the 
significant and potential savings of the Army were cited as compared to costs of traditional classroom instruction:

"The Army could save $\$ 114$ million in per diem costs alone simply from the reduction of instructional time in schoolhouses that would be delivered by the implementation of computer-based self-paced learning. Training on an as required basis within the home station, will help to ensure that people will possess needed skills that will be well honed while they are in the unit rather than be at their peak when they are in the schoolhouse. Effective training systems could generate personnel, acquisition, or operational savings. ${ }^{.53}$

The next section will highlight recommended programmatic changes from providing traditional operational readiness training to the Services to leveraging and exploiting advanced technology. This paradigm shift in focus must correlate with the training transformation doctrine developed to expand the evolution of advanced technology targeted to the FYDP.

\section{RECOMMENDATIONS}

The following recommendations are necessary for the successful implementation of ADL and $\mathrm{DL}$ in the Air Force and Army. These recommendations are based on my research and personal and professional experience in the higher education and technical training arenas. ${ }^{54}$ The recommendations will be presented in broad, general categories to more specific ones.

Leaders must set the climate for leveraging technology in training and encourage their personnel to take full advantage of advanced technology training platforms. The exploitation of advanced distributed learning and distance learning parameters in training must be widened from its more narrow focus of losing instructor personnel (a misnomer) or minimal group dynamics in using these concepts in formal classroom environments to a full understanding on how the DL can supplement and enhance the instructor-led lessons. ${ }^{55}$ This climate change can lead to a culture shift fully aided by changed leadership attitudes and an understanding of the benefits of leveraging advanced technology in the schoolhouses and combat training centers. Unfortunately, the Services continue to resist embracing the new training technology focused on learner centric training versus the traditional, instructor led training at the formal classroom. ${ }^{56}$

Training manpower standards for ADL and DL should be established for a permanent staff position at the unit level to work with advanced technology as the subject matter expert (SME) on the training equipment and skills proficiencies. The responsible staff member will act as the primary training consultant for the commander. The SME should play an active role from tooth to tail - from the defining milestones of the identified training requirements (design, development, acquisition, and evaluation) of the equipment or new training venue to ensure operational 
readiness is thoroughly integrated. ${ }^{57}$ This recommendation is supported by the Defense Science Board Task Force when they cited the need for devoting the proper time, leadership affirmation and full time personnel attention to alternative delivery platforms for training success:

"Distributed learning cannot be viewed as an "other duties as assigned" [additional duty] activity. It is not enough to make distributed learning materials available, it must be given the same priority as established readiness indicators. ....in the final analysis a 'ready' force is a trained force. ${ }^{.58}$

All MAJCOMs/MACOMs should submit training requirements in readiness and sustainment training to their respective career field and functional managers to take advantage of targets of opportunity for critical specialties or skills progression. This will be accomplished on a Total Force basis - including active duty, guard, and reserve requirements. This in-depth study also ties into budget proposals on the projected advanced distributed learning and distance learning milestones previously indicated by higher headquarters guidance and direction. ${ }^{59}$ If the unit training managers are not aware of changes to courses made by the career field managers or functional managers, the courses are not scheduled properly. Hence, the soldiers and airmen do not get the training when they need it during their career progressions.

The Services should build a broader partnership with industry and education institutions benchmarking practices and emulate those that will accelerate the training of military personnel and incorporate training transformation concepts. Military training venues have a tendency to be stove piped and rigid in their approaches to training the troops. The idea of embracing new practices in a more formal training environment is slow to materialize. ${ }^{60}$ The demand for new equipment and technology comes from the field first due to the missions and the utilization of unit personnel deploying with this equipment. This is also indicative of embracing technology to attract new recruits, as well as retaining current military personnel with creative and innovative means of providing readiness and sustainment training. This could be accomplished by having the AETC and TRADOC leadership be the "champions" for advanced technology (acquisition, funding, investment, and inculcation of exploiting advanced technology throughout the MAJCOM/MACOM) and take the gauntlet of shifting the training mission from providing a predominately rigid, traditional training environment to one that embraces the significant opportunities of advanced technology. ${ }^{61}$

The Services should target an additional 5 percent of conversion rates instead of only focusing on the 30 percent set by the initial SECDEF ADL and DL training guidance. This sets the standard higher and will spearhead a more positive response for additional funding on 
advanced training technology mandates. The overall potential for resource and manpower savings, due to decreased TDY, per diem costs and PERSTEMPO and OPTEMPO, will significantly benefit operational readiness. ${ }^{62}$ This measure is indicative of actively transforming to a transformed environment. According to the DoD ADL Implementation Plan, "The benefits of investing in Training Transformation will be far reaching and will form the foundation that will enable the attainment of the Department's broader Transformation objectives. ${ }^{63}$

\section{CONCLUSION}

Department of Defense and Service specific guidance and policies mandate to lower echelons the incorporation of advanced distributed learning and distance learning in all aspects of training. Capitalizing on this mandate is the opportunity to provide timely training in an environment where fast-paced operations and high personnel tempos are the norm. Leadership must remain positive and spread the word concerning the advantages of using technology in readiness training. Advanced technology is not a new concept. Our changing world environment dictates that the operational readiness of military personnel to be prepared for multiple mission taskings. The philosophy of adopting advanced distributed learning and distance learning applications permeates throughout the DoD ADL Implementation Plan. It states, "The addition of ADL capabilities to traditional Armed Forces education and training programs provides powerful new tools to establish, improve, and maintain the skills of American soldiers, sailors, airmen, and marines. ADL empowers 'learner centric' education and training, marking a shift from the current classroom and distance teaching philosophy to a model of anytime, anywhere learning. ${ }^{.64}$

WORD COUNT $=8,100$ 


\section{ENDNOTES}

${ }^{1}$ George W. Bush, The National Security Strategy of the United States of America

(Washington, D.C.: The White House, September 2002), 31.

${ }^{2}$ Department of Defense, Training Philosophy (Washington, D.C.: U.S. Department of Defense, October 1998), 1.

${ }^{3}$ Department of Defense, Military Training, DoD Directive 1322.18 (Washington, D.C.: U.S. Department of Defense, 28 December 1993), 7.

${ }^{4}$ Ibid.

${ }^{5}$ Department of Defense, Strategic Plan for Transforming DoD Training (Washington, D.C.: U.S. Department of Defense, 1 March 2002), 1.

${ }^{6}$ lbid.

${ }^{7}$ Ibid.

${ }^{8}$ Department of the Army, Training the Force, Army Field Manual 25-100 (Washington,

D.C.: U.S. Department of the Army, November, 1988), 1.

${ }^{9}$ Department of the Army, Peace Operations, Army Regulation 100-23 (Washington, D.C.: U.S. Department of the Army, December, 1994), 86.

${ }^{10}$ lbid.

${ }^{11}$ Ibid.

${ }^{12}$ Robert F. Holz, Jack H. Hiller, and Howard H. McFann, eds., Determinants of Effective Unit Performance: Research on Measuring and Managing Unit Training Readiness (Alexandria, VA: U.S. Army Research Institute for the Behavioral and Social Sciences, 1994), 24.

${ }^{13}$ Ibid.

${ }^{14}$ Ibid.

${ }^{15}$ Department of the Air Force, Readiness, Air Force Policy Directive 10-2 (Washington D.C.: U.S. Department of the Air Force, 1 March 1997), 1.

${ }^{16}$ Ibid.

${ }^{17}$ Ibid.

${ }^{18}$ Department of the Air Force, Managing, Developing, and Conducting Training, Air Force Instruction 36-2201 (Washington, D.C.: U.S. Department of the Air Force, October 2002). This directive specifies details on the training continuum of an enlisted person's career, describes accompanying documentation for training at the major command (MAJCOM) and unit levels, and 
specifies roles and responsibilities at the schoolhouse, squadron, group, MAJCOM, and higher headquarters.

${ }^{19}$ Air Education and Training Command (AETC) is the Air Force focal point for training technology, training development, and formal training programs. Major Commands (MAJCOMs) are responsible for identifying military training and resource requirements, establish supplementary programs, and execute the programs to comply with higher headquarters policy.

${ }^{20}$ AETC doctrine dictates the formal schoolhouse requirements provided by AETC instructors, training management personnel, and facilities. "Group step" is the progression of the students as an aggregate and can be accelerated in the block of instruction. "Lock step" is the progression of the students on a pre-determined schedule and cannot vary from it during the course of instruction.

${ }^{21}$ Michael Hardesty and Jason D. Ellis, "Training for Peace Operations: The U.S. Army Adapts to the Post-Cold War World," Peaceworks, no. 12 (1997): 21. Unit training and CTCs have adapted to advanced technologies by the utilization of simulation and other training equipment to provide optimal use of humanitarian operation and peacekeeping scenarios the Army soldier may encounter while deployed.

22 "Pre-deployment Training," CTC Trends for JRTC 01-6 (March 2001): 11. Operational documents were not available during scenarios on standard operating procedures, plus senior enlisted personnel were not sufficiently trained on the new equipment to provide a subject matter expert approach to training the troops. This led to a detriment in operational readiness and therefore, training days had to be lengthened.

${ }^{23}$ Dr. Ralph Chatham and Dr. Joe Braddock. "Training Superiority and Training SurpriseFinal Report", briefing slides with scripted commentary, Washington, D.C.: Defense Science Board Task Force, 12 December 2000.

${ }^{24}$ Ibid.

${ }^{25}$ Ibid.

${ }^{26}$ Department of Defense, Implementation Plan for Advanced Distributed Learning, (Washington, D.C.: U.S. Department of Defense, 19 May 2000), ES-2.

${ }^{27}$ Keith J. Costa, "Top Pentagon Official Urges Quick Action on Training Transformation," Inside the Pentagon November 2002 [periodical on-line]; available from http://ebird.dtic.mil/Nov2002/s20021121126401.html; Internet; accessed 21 November 2002.

${ }^{28}$ Department of Defense, Implementation Plan for Advanced Distributed Learning, (Washington, D.C.: U.S. Department of Defense, 19 May 2000), 5.

${ }^{29}$ Department of the Army, Army Modernization Plan 2002. Annex C, Training and Leader Development, (Washington, D.C.: U.S. Department of the Army, February 2002), 12. 
${ }^{30}$ Department of Defense, Implementation Plan for Advanced Distributed Learning,

(Washington, D.C.: U.S. Department of Defense, 19 May 2000), 8.

${ }^{31}$ Michael Briggs, "Students Take Giant Steps Using New Technology," Air Force News December 2002 [journal on-line]; available from <http://www.airforcelink.mil/today's air force news.html>; Internet; accessed 14 December 2002.

32 Donald W. Campbell, "The Privatization of Military Training Would Benefit U.S.," Training and Simulation Trends and Technology Review 2002, (November 2002): 66.

${ }^{33}$ Department of Defense, Implementation Plan for Advanced Distributed Learning, (Washington, D.C.: U.S. Department of Defense, 19 May 2000), 24.

${ }^{34}$ My experience stems from my years as an Interactive Courseware Manager and Distance Learning Manager for medical technical training at the schoolhouse and group levels, program manager for civil engineering training, and working at Headquarters Air Force in military training venues for joint and Services training.

${ }^{35}$ Michael G. Shanley, Henry A. Leonard, and John D. Winkler, Army Distance Learning: Potential for Reducing Shortages in Army Enlisted Occupations. (Washington, D.C.: Rand Publishing Co., 2001), Summary xii.

${ }^{36}$ Department of Defense, Strategic Plan for Transforming DoD Training (Washington, D.C.: U.S. Department of Defense, 1 March 2002), 24.

${ }^{37}$ Department of the Air Force, Report of Other Services' Advanced Distributed Learning Practices, U.S. Air Force Advanced Distributed Learning Strategic Plan (Washington, D.C.: U.S. Department of the Air Force, 3 April 2002), 75.

${ }^{38}$ William M. Steele and Robert P. Walters, Jr., "Training and Developing Leaders in a Transforming Army," Military Review 81 (September-October 2001): 7.

${ }^{39}$ Department of the Army, Army Modernization Plan 2002, Annex C, Training and Leader Development, (Washington, D.C.: U.S. Department of the Army, February 2002): 13.

${ }^{40}$ Ibid.

${ }^{41}$ Ibid.

42 lbid.

${ }^{43}$ Department of the Air Force, "The Road Ahead", Chief's Sight Picture (May 2002): 1.

${ }^{44}$ Department of Defense, Military Training. DoD Directive 1322.18. (Washington, D.C.: U.S. Department of Defense, 28 December 1993), 12.

${ }^{45}$ Roxana Tiron, "U.S. Army Training Conforms to Shifts in Strategy, Tactics," Training and Simulation Trends and Technology Review 2002, (November 2002): 32. 
${ }^{46}$ Michael G. Shanley, Henry A. Leonard, and John D. Winkler, Army Distance Learning: Potential for Reducing Shortages in Army Enlisted Occupations. (Washington, D.C.: Rand Publishing Co., 2001), 8.

${ }^{47}$ Department of Defense, Implementation Plan for Advanced Distributed Learning, (Washington, D.C.: U.S. Department of Defense, 19 May 2000), Summary ES-1.

${ }^{48}$ Ibid.

${ }^{49}$ Michael G. Shanley, Henry A. Leonard, and John D. Winkler, Army Distance Learning: Potential for Reducing Shortages in Army Enlisted Occupations. (Washington, D.C.: Rand Publishing Co., 2001), 12.

${ }^{50}$ Gary Twogood <gary.twogood@randolph.af.mil>, "ADL/DL Conversion Costs," electronic mail message to Kathy Lindsey <kathy.lindsey@pentagon.af.mil>, 7 May 2002.

${ }^{51}$ Department of Defense, Implementation Plan for Advanced Distributed Learning, (Washington, D.C.: U.S. Department of Defense, 19 May 2000), 58.

${ }^{52}$ Michael Briggs, "Students Take Giant Steps Using New Technology, " 5 December 2002; available from <http://www.airforcelink.mil/today's air force news.html>; Internet. accessed 14 December 2002.

${ }^{53}$ Dr. Ralph Chatham and Dr. Joe Braddock, "Training Superiority and Training SurpriseFinal Report", briefing slides with scripted commentary, Washington, D.C.: Defense Science Board Task Force, 12 December 2000.

${ }^{54}$ These recommendations are based on my experience working as a consultant in different training specialties (including critical AFSCs) for the Air Force. They are also offered as potential solutions for mandated guidance of course conversion.

${ }^{55}$ Numerous training managers are hesitant to capitalize on lesson, objective or course conversion because they believe that if the course was shortened [due to ICW factors], then the instructor staff would be cut. Therefore, they did not fully comprehend the benefits that ICW would entail, or allow their students to ICW lessons as remediation tools.

${ }^{56}$ Department of the Air Force, Report of Other Services' Advanced Distributed Learning Practices, U.S. Air Force Advanced Distributed Learning Strategic Plan (Washington, D.C.: U.S. Department of the Air Force, 3 April 2002): 77.

57 Numerous unit training managers are pulled from other jobs at their work center and can not devote the time necessary to analyze and process their units' training requirements. Also, the new unit training managers were not sufficiently trained by their predecessors (either in person or by a continuity book) and had to learn through mistakes or through higher headquarters personnel on managing their requirements. 
${ }^{58}$ Dr. Ralph Chatham and Dr. Joe Braddock, "Training Superiority and Training SurpriseFinal Report", briefing slides with scripted commentary, Washington, D.C.: Defense Science Board Task Force, 12 December 2000.

${ }^{59}$ During the data call for training requirements from Air Force and Army MAJCOMs/MACOMs, problems are encountered when the career field and functional managers are not kept in the loop of the aggregate training requirements of the field personnel. Significant changes can be made in several AFSCs or MOSs, which required new courses be developed and funded, or current courses to be extended or expired. When this occurs, old courses are "dropped" during the FYDP, and new course identifiers are indicated in the data base.

60 The technical training wings are usually among the last to receive new training equipment or technologies due to the field needing the equipment. Also, the training commands for the Army and Air Force are based on the "throughput" (how many students graduate from technical training and sent to their duty assignments) mechanism of getting personnel trained in large numbers. This normally translates to standardized, traditional classroom training.

${ }^{61}$ The mission of AETC and TRADOC is to provide timely training for their personnel predominately through formal classroom instruction and delivery. The growth of training technology has been spearheaded mostly through the higher headquarters mandates and seen as a funding and requirements burden to the services.

62 Since 1995, the Services have used the 30 percent mark as a gauge for their overall conversion rates. This percent ratio has remained static since that year and shows no growth potential for the Services.

${ }^{63}$ Department of Defense, Implementation Plan for Advanced Distributed Learning, (Washington, D.C.: U.S. Department of Defense, 19 May 2000), 24.

${ }^{64}$ Ibid. 


\section{GLOSSARY}

ADL

AETC

AFSC

$A F$

AFI

AFPD

CBI

CBT

CONOPS

CTC

DL

DoD

DPG

$F Y$

FYDP

ICW

IVT

MACOM

MAJCOM

MOS

NSS

OJT

OPTEMPO

PERSTEMPO

POM

QDR

RMA

ROI

SECDEF

SME

TDY

TI

TRADOC

VTT

WBT
Advanced Distributed Learning

Air Education and Training Command

Air Force Specialty Code

Air Force

Air Force Instruction

Air Force Policy Directive

Computer Based Instruction

Computer Based Training

Concept of Operations

Combat Training Center

Distance Learning

Department of Defense

Defense Planning Guidance

Fiscal Year

Fiscal Year Defense Program

Interactive Courseware

Interactive Video Teletraining

Major Command (Army)

Major Command (Air Force)

Military Occupational Specialty

National Security Strategy

On the Job Training

Tempo of Operations

Tempo of Personnel

Program Objective Memorandum

Quadrennial Defense Review

Revolution in Military Affairs

Return on Investment

Secretary of Defense

Subject Matter Expert

Temporary Duty

Technology Insertion

Army Training and Doctrine Command

Video Teletraining

Web-based Training 


\section{BIBLIOGRAPHY}

Briggs, Michael. "Students Take Giant Steps Using New Technology." 5 December 2002. Available from <http://www.airforcelink.mil/today's air force news.html>; Internet. Accessed 14 December 2002.

Bush, George W. The National Security Strategy of the United States of America Washington, D.C.: The White House, September 2002.

Campbell, Donald W. "The Privatization of Military Training Would Benefit U.S." Training and Simulation Trends and Technology Review 2002, (November 2002): 66-70.

Chatham, Dr. Ralph, And Dr. Joe Braddock. "Training Superiority and Training Surprise-Final Report." Briefing slides with scripted commentary. Washington, D.C.: Defense Science Board Task Force, 12 December 2000.

Costa, Keith J. “Top Pentagon Official Urges Quick Action on Training Transformation.” Inside the Pentagon November 2002. Periodical on-line. Available from http://ebird.dtic.mil/Nov2002/s20021121126401.html. Internet. Accessed 21 November 2002.

Hardesty, J. Michael, and Jason D. Ellis. "Training for Peace Operations: The U.S. Army Adapts to the Post-Col War World." Peaceworks, no. 12 (1997): 21-26.

Holz, Robert F., Jack H. Hiller, and Howard H. McFann, eds. Determinants of Effective Unit Performance: Research on Measuring and Managing Unit Training Readiness. Alexandria, VA: U.S. Army Research Institute for the Behavioral and Social Sciences, 1994.

"Pre-deployment Training." CTC Trends for JRTC 01-6 (March 2001): 71-86.

Shanley, Michael G., Henry A. Leonard, and John D. Winkler. Army Distance Learning: Potential for Reducing Shortages in Army Enlisted Occupations. Washington, D.C.: Rand Publishing Co., 2001.

Steele, William M., and Robert P. Walters, Jr. "Training and Developing Leaders in a Transforming Army." Military Review 81 (September-October 2001): 7-14.

Tiron, Roxana. "U.S. Army Training Conforms to Shifts in Strategy, Tactics." Training and Simulation Trends and Technology Review 2002, (November 2002): 32-36.

Twogood, Gary < gary.twogood@randolph.af.mil>. "ADL/DL Conversion Costs." Electronic mail message to Kathy Lindsey <kathy.lindsey@pentagon.af.mil>.7 May 2002.

U.S. Department of the Air Force. Managing, Developing, and Conducting Training. Air Force Instruction 36-2201. Washington, D.C.: U.S. Department of the Air Force, October 2002.

U.S. Department of the Air Force. "The Road Ahead." Chief's Sight Picture (May 2002). 
U.S. Department of the Air Force. Distributed Learning: Best Practices in Industry, Academia, and Governmental Agencies. U.S. Air Force Advanced Distributed Learning Strategic Plan. Washington, D.C.: U.S. Department of the Air Force, 3 April 2002.

U.S. Department of the Air Force. Readiness. Air Force Policy Directive 10-2. Washington, D.C.: U.S. Department of the Air Force, 1 March 1997.

U.S. Department of the Air Force. Report of Other Services' Advanced Distributed Learning Practices. U.S. Air Force Advanced Distributed Learning Strategic Plan. Washington, D.C.: U.S. Department of the Air Force, 3 April 2002.

U.S. Department of the Army. Army Modernization Plan 2002. Annex C, Training and Leader Development. Washington, D.C.: U.S. Department of the Army, February 2002.

U.S. Department of the Army. Peace Operations. Army Regulation 100-23. Washington, D.C.: U.S. Department of the Army, December 1994.

U.S. Department of the Army. Training the Force. Army Regulation 25-100. Washington, D.C.: U.S. Department of the Army, November 1988.

U.S. Department of Defense. Implementation Plan for Advanced Distributed Learning. Washington, D.C.: U.S. Department of Defense, 19 May 2000.

U.S. Department of Defense. Military Training. DoD Directive 1322.18. Washington, D.C.: U.S. Department of Defense, 28 December 1993.

U.S. Department of Defense. Strategic Plan for Transforming DoD Training. Washington, D.C.: U.S. Department of Defense, 1 March 2002.

U.S. Department of Defense. Training Philosophy. Washington, D.C.: U.S. Department of Defense, October 1999. 